\title{
Managing human capital to engineer process improvement for team interfaces: a case study
}

\author{
Debashish Sengupta, Ray Titus \\ School of Business, Alliance University, Bangalore, India
}

\begin{abstract}
Process improvements of existing team interfaces in the organisation Zygus Engineering India Pvt Ltd are used in this case study to explore challenges in human resource management of project-based organisations. The findings suggest that both design and interventions in engaging human capital, and their subsequent impact, play a critical role in determining the effectiveness and efficiencies in project team environments.
\end{abstract}

Keywords: Human Resource, Process Improvement, Team Interface, Project Management

\section{Introduction}

Projects, flexibility, cross-functional teams, and deadlines are buzzwords in today’s workplaces. Mainstream management rhetoric refers to the ideal 'project worker' as competent and knowledgeable, flexible, a team worker, and responsible for staying employable. Projects are the everyday work environment for these individuals. Their competence and careers are built upon project participation; their performance in the projects is what gives them their reputation and makes them sought after for future projects. Several studies suggest that contemporary firms to a greater extent perform their operations by the means of projects, project management and various types of project-like structures in order to increase flexibility and integrate knowledge resources in a more efficient way. For example, Whitley (2006) argues that temporary work systems and project-based organisations can be interpreted as representing a 'new logic of organizing' . Similarly, Midler (1995) refers to fundamental changes in companies, where the number of projects to be managed has?

multiplied, and the broad study by Whittington, et al (1999) gives empirical support to the increased use of project-based structures among European firms.

\section{Literature review}

Project-based organisations

The trend of 'projectification' in modern industry has been accompanied by increased research interest. Over the past 20 years, research into project management and project organising has developed considerably, and it has dealt with a wide range of topics concerning, for example, alternatives to functional structures, knowledge management processes, multi-project management, and the problems of inter-project learning and innovation processes (Söderlund, 2004). The increased use of project-based structures is interpreted by many as being part of a general shift from bureaucratic to post-bureaucratic organisations, which are 'knowledge-based', in constant change, in which the organisational borders are more indistinct, and in which people work in decentralised structures of autonomous project teams (e.g., Hatch 1997; Heydebrand 1989). Others question whether project management is actually used to increase flexibility and autonomy, and argue instead that the development of project structures is a sign of a 'rebureaucratisation' of contemporary organisations. For example, Hodgson (2004) suggests that 
“project management can be seen as an essentially bureaucratic system of control” (p. 86), and that "much of the recent expansion of the field of project management, particularly within the 'post-bureaucratic' organization, reflects its asserted ability to impose traditional 'bureaucratic' virtues of predictability, accountability, surveillance and control over the 'knowledge workers' of the "New Economy"' (p.98). Whether the development of project management is a way to promote flexibility and autonomous teamwork or a way to control it, the increased use of projectbased structures implies that projects have become a common work environment. This means that more time is spent on project work (Packendorff 2002; Whittington, et al 1999), more people build their careers through projects (e.g., Arthur \& Parker 2002), and projects become the basic unit for core activities in contemporary organisational forms (Hobday 2000; Sydow, et al 2004).

Moreover, a number of authors argue that the move towards project-based structures has implications for management, employee relations, and employment contracts; some positive and others negative. For example, the study by Hovmark and Nordkvist (1996) of engineers in companies where project matrixes have been implemented, demonstrates that these engineers perceive a number of positive changes in terms of increased commitment, dynamism, support and solidarity, communication and group autonomy. But, there are also critical voices that plead for a more balanced view of project work that also takes negative factors into account. For example, Packendorff (2002) argues that projects rarely take previous experience and workload of an individual into account, which creates a continuously high intensity work environment. Similarly, Zika-Viktorsson, et al (2006) discuss the problem of 'project overload'. Their survey reveals that project work, particularly in multi-project environments, enhances the risk of excessive workload with little time for reflection, learning and recuperation between the projects. The study also shows that these issues lead to stress reactions and might hamper competence development. Engwall, et al (2003:130) put forth similar concerns, and furthermore, they state that this calls for more empirical studies into human resource management (HRM):

As organizations move into project-based structures, human resource management, hiring of staff, and competence development all seem to be affected. Furthermore, issues concerning working life must be readdressed in this new corporate context design. From the perspective of the individual employee, factors like motivation, commitment, empowerment, job satisfaction, time pressure, and medical stress seem to be re-conceptualized in the projectified context. Working life issues also include accounts of project work as a new career path and as ways of linking project organizations to individual goals.

\section{Effect of temporal nature of organisations on HRM practices}

There is a great deal of stress in modern organisations on projects and project management to achieve greater levels of efficiency and flexibility in integrating knowledge resources. Contemporary firms put greater emphasis on projects, project management, and various types of project structures to increase flexibility and more effectively integrate knowledge resources. Hence, many contemporary organisations have embraced the physiognomies similar to the project-based organisation, particularly in knowledge-intensive industries, high-velocity industries, and in industries producing complex products and systems (Hobday, 2000). Several studies indicate that project-based structures have significant implications on the employees. Consequently, the HRM is also significantly impacted. For example, Manuel Castells states that "the actual operating unit becomes the project, enacted by a network, rather than individual companies or formal groupings of companies” (Castells, 1996). In project-based organisations, 
the important elements of permanence are lost and 'throw-away personnel policies, where emphasis is placed on selection and turnover rather than on training and learning, have become common in modern business, politics and marriage' (March, 1995). The projects are discontinuous, short-term and complex, stringently limited in time, with limited resources and high levels of unpredictability, and this is related to HRM and to the organisation's ability to create a unique product, service or process (Geraldi 2008).

Project-based organisations face various challenges in HRM, such as: comparatively higher role strain than traditional organisations (Goodman 1981); excessive workload due to multi-project environments and hence less time for reflection, learning and recuperation between the projects (Zika-Viktorsson, Sundstrom \& Engwall 2006); stress reactions that might hamper competence development (Packendorff 2002); individual responsibility for the attainment of the competencies required (Huemann, Turner \& Keegan 2004); and difficulties in planning and preparing training development because individuals are taking more responsibility to finish the project in time (Bredin \& Soderlund 2006). Projects are temporary in nature and hence career development opportunities for employees may not be always assured. Individual careers are shaped by the availability of projects (Grabher, 2002). The project-based organisation creates a new work environment that involves human resource development from the the individual employee's perspective of, competence development, motivation, commitment, empowerment, job satisfaction, time pressure and work stress (Stulgienė \& Čiutienė 2012).

Given such unique challenges in managing the workforce, the project-based organisation stands out as a highly relevant organisational context for research into HRM (Midler 1995). Projectbased settings are becoming increasingly common, particularly in contemporary knowledgeintensive industries.

Second, it seems to have certain characteristics that emphasise the importance of HRM but that, at the same time, challenge existing models and practices of HRM. This was, for example, shown in the broad survey by Whittington et al (1999: 591): "Decentralised and more intensely interacting organisations need new kinds of human resource practices ... Thus, there seemed to be considerable increases in the emphasis put on human resource management to provide the skills and the glue to make the flatter and more horizontal structures work.”

Accordingly, this research explores how HRM is challenged by the project-based organisation and how organisations change their ways of performing HRM to handle these challenges. In the following sections, I will discuss three important trends in contemporary working life and HRM that are particularly relevant in relation to the increased use of project-based structures. After that, the argument for studying HRM in project-based organisations will be further elaborated upon and an overview of existing research related to the topic presented. 


\section{Development of HRM in project-based organisations}

The focus of this research is HRM in project-based organisations. However, the development of HRM in such organisations is, of course, part of a more general development of HRM and of trends linked to HRM issues in a wider industry context. A project-based organisation is defined here as an organisation that privileges strongly the project dimension concerning its core activities and carries out most of these activities in projects (cf. Hobday 2000; Lindkvist 2004). This means that, in such organisations, people mainly work in temporary project constellations. HRM is defined as the area of management that concerns the management of the relation between people and their organisational context (cf. Beer, et al 1984; Brewster \& Larsen 2000).

In essence, this research explores the challenges that HRM meet in project based organisations and the changes that are made in people management systems in order to align them to the project-based organisational context. This explorative research also provides a foundation for new concepts and theoretical constructs that can be used for the analysis of HRM in project based organisations. The case contributes primarily to research and practice in project-based organizations, since it puts existing HRM concepts and management practices in a particular organisational context under scrutiny.

Case study

In choosing Zygus Engineering ${ }^{1}$ as the focus of the research, an attempt was made to study a project-based organisation facing challenges in the way it operated with a temporal business model that needed to be tweaked based on the project undertaken. The complexities of managing human capital at Zygus provided for a comprehensive study of human resource engagement issues at a project-based organisation.

\section{Rationale behind the choice of the case study methodology}

Case studies contribute to the building of a professional repertoire (Schön 1991). A case study and, normally, history focus on one case, but simultaneously take account of the context, and so encompass many variables and qualities, following an "explicative" strategy as opposed to "experimental" (one unit of analysis and a few isolated variables) or "reductive" (many units of analysis and a few variables) strategies (Johansson 2002).

A case study is expected to capture the complexity of a real situation. . The "case" should

- $\quad$ be a complex functioning unit,

- $\quad$ be investigated in its natural context with a multitude of methods, and

- be contemporary.

Case studies combine the other research strategies like qualitative and interpretive research, Correlational research, Experimentation, Logical argumentation and Simulation methods. In that respect the case study could be said to be a meta-method (Groat \& Wang 2002). Case study research is difficult and presents the researcher with unique challenges (Yin 1994; Dubē and Parē 2003; Darke et al 1998). Case studies are most commonly qualitative, and this places a heavy emphasis on the individual contribution and choices of the researcher. The researcher seeks an in-depth understanding of the interaction between phenomenon and context. He or she

\footnotetext{
${ }^{1} 1$ Zygus Engineering is an alias for the actual project-based engineering company that was the focus of the case study.
} 
may collect data on many variables; the challenge is to identify those variables of significance to the phenomenon under investigation (Benbasat et al 1987; Remenyi \& Williams 1995).

Our objective to understand the various aspects of managing Human Capital to Engineer Process Improvement for Team Interfaces led us to use the case study method. Studying process improvements of existing team interfaces in an organisation was best done by using a case study considering the fact that case study can capture the complexity of a real situation in complex functioning unit and hence could be used to explore challenges in HRM of project-based organisations. The findings from the case study suggest that both design and interventions in engaging human capital, and their subsequent impact, play a critical role in determining the effectiveness and efficiencies in project team environments.

Robert Yin (1994) placed more emphasis on methods when it comes to case study, but Robert Stake (1998) gave a much more inclusive definition of a case study: "As a form of research, case study is defined by interest in individual cases, not by the methods of inquiry used." The case presented in the study conforms to Stake's definition. The case investigates a present-day phenomenon in a real-life setting, and the focus is on organisational and managerial (rather than technical) issues (Myers 2003). These are exactly the issues identified as best suited to case study research. The experiences of the agents are critical, and intelligible only within the social and cultural context of the industry.

\section{Background of Zygus Engineering India Pvt Ltd}

This case research was based on a study of Zygus Engineering India Pvt Ltd (ZEI), a projectbased organisation. One of the toughest challenges that such organisations face is improving team interfaces and thereby impacting process improvements. At the core of such initiatives at the team interface level lies enhanced interventions at the HRM level.

Zygus Engineering, a division of the Zygus Group, is a leading worldwide technology partner for plant engineering and construction. Zygus's global success is built on its extensive process engineering expertise in the planning, project development and construction of turnkey industrial plants. With more than 1,000 process engineering patents and 4,000 completed plant projects, Zygus ranks among the leading international plant contractors.

Zygus Engineering India Pvt Ltd (ZEI) was established in 1987 with its Indian operation head office in the city of Vadodara. ZEI has grown over the years to develop a talent pool of over 750 employees. Being a 100\% subsidiary of Zygus Engineering, ZEI has integral access to Zygus Engineering's technology and project execution know-how.

The Zygus Group is a rich collection of businesses and brands, each with its own history and legacy. It is a world-leading gases and engineering company with approximately 50,000 employees working in more than 100 countries worldwide, with different cultures, traditions, languages, beliefs and styles. In the 2012 financial year, it achieved sales of EUR 14 bn.

Zygus's core values and foundational principles provide a framework that helps to guide their decisions and actions. Four core values that differentiate Zygus from their competitors are Desire to excel, Innovating for customers, Empowering people and Flourishing through diversity. This 
framework has a major influence in the way employees at Zygus engineering deal with each other and with their customers, and sets standards for engaging with other stakeholders. It affects the way employees are viewed, as individuals and groups, both inside and outside the organisation. In fact, the whole process of scripting values for the organisation had been a collaborative process when the company was founded in 2005. Zygus's core values express what the company stands for and the way in which it differentiates itself from rest of the players in the industry.

Decades of Zygus's engineering excellence substantiates ZEI's capabilities in delivering engineering, procurement and construction services for major market segments such as: petrochemical plants, liquefied natural gas (LNG) and LNG processing plants, synthesis gas plants, hydrogen plants, gas processing plants, cryogenic plants, furnaces for petrochemical plants and refineries, etc. ZEI has credibility in rendering sulfur recovery plants, refinery process plants, off-sites and utilities plants including large storage tanks and CO2 removal/recovery plants. ZEI also provides engineering consulting services for plant revamp and other brownfield projects

\section{Methodology}

Statement of the problem

The objectives of this research are to identify unique HR challenges in ZEI and how effectively HRM activities can be applied to it. The research also focuses on addressing the employee's perception of the HR role and effectiveness in project-based organisations. The various HR challenges and problems faced at managerial level can be identified. The managers can be given an insight of the role of HR to take part in the employee's performance activities efficiently. Through this research the HRM gaps can be identified and suggestions could be provided for the ways to fill those gaps. The main objectives of the research is to conduct a fair and free-flowing review of each and every employee in a project team regarding their performances, and to motivate the employees for much better productivity and growth of the organisation. The research also aims to understand HRM as an area of management in which various players share the responsibility for its design and performance and thereby impact process improvement of existing team interfaces.

\section{Methodology}

The data were collected from focus group interviews with several project teams as well as through an in-depth interview of HR executives and line managers. This was done by designing a questionnaire related to the usefulness and implications of HRM in the project teams. 


\section{Research design}

The research is a cross-sectional descriptive study on the impact of HR in project-based teams. It is descriptive research analysis that describes the data and characteristics about the population or phenomenon being studied. In order to find the impact of HRM in project-based teams, openended questions were designed for the four categories of employees in an organization, namely:

1. HR Executives

2. Team Leaders/Project Managers

3. Team Members

4. Industry Experts

The in-depth interview was with HR and project managers and the focus group interview were with team members to analyse their views on the possible involvement of HR in project-based teams.

\section{Data collection methods}

The data used in the study are from both primary and secondary sources.

Primary data: The primary data were collected using structured, open-ended questionnaire responses from the employees and trainees in the project teams. The primary data were also collected from the managers and industrial experts to give a broader view of the research analysis in perspective. Surveys were administered to team employees, managers and experts on a voluntary basis during their work hours.

Secondary data: The secondary data were collected from the company directly in order to find out about the various active HR policies used for managing the people efficiently.

\section{Data collection source}

The survey population includes several HR executives, line managers, team members and industrial experts through different sets of questionnaires for each category. The sample composition is as follows:

\section{Table 1: Sample composition \& size}

\begin{tabular}{|l|l|}
\hline Sample Composition & Sample Size \\
\hline HR Managers & 5 \\
\hline Team Leaders / Project Managers & 5 \\
\hline Team Members & 5 teams \\
\hline Industry Experts & 2 \\
\hline
\end{tabular}

\section{Sampling method}

The sampling method used in this study is purposive sampling. A judgement on the organisation in terms of its appropriateness for this study was the prime driver behind the use of the sampling method. 


\section{Findings and analysis}

Interview protocol

All interviews were conducted on location. Specific time periods were scheduled. All interviews were recorded for transcription and analysis. Informed consent to the interviews were given by the participants by reading and signing the interview protocol forms.

\section{Analysis tools}

The questionnaire used open-ended questions where employees and managers were free to express their opinions in detail. Since the techniques used were in-depth and focus group interviews, statistical tools were not necessary for analysis of the data. The relevant points were analysed and based on the participants' comments and feedback.

\section{Focus group questionnaire for project team members}

HR plays a support role in handling the team's functional aspects and is closely associated with the performance of every employee in the team and in providing the necessary feedback efficiently. HR's role is also to provide the sufficient resources for the team, based on the types of projects assigned, and it provides a supporting role in managing the team. The employee engagement activities should be done in order to motivate the employees in a team for better performance outcome. The employee engagement activities should show a proper understanding of cross-cultural diversities in order to ensure greater unity within the team. Performance-based incentives should be given for the right kind of talents in order to motivate employees to perform better within a team.

There should be a good combination of both individual as well as team-based performance evaluation in order to clearly understand the performance level of the team in an efficient way. The compensation setup should be purely based on the performance of the individual in the specific project and his or her contributions to it. The compensation setup should also be based on the experience level on grade basis. This helps in bringing a proper hierarchy within an organisation.

There should be proper communication between HR and the project managers in handling the training process for the team efficiently. The analysis also suggests that the communication gap should be shortened between employees and their managers in order to provide the training process efficiently. The obstacles in performance evaluation occurs due to the wide communication gap between team members and the project managers. The gap should be removed in order to ensure better evaluation of the performance of each team member. The individual contribution should always be highlighted higher than that of the team.

HR plays an important role in improving the work-life balance for employees. The need for getting employees involved in more challenging projects should also be an HR responsibility in order have a proper competency mapping.

\section{In-depth interview questionnaire for project managers}

The allocation of tasks is based on the mix of project's priority for completion, skill sets required from the team members as well as common random allocation. This task allocation is done by the project managers and HR plays a supportive role in providing the right kind of skills 
at the right time. The project managers will coordinate with the HR managers during the competency mapping in order to advise HR on the type of skill sets required based on the project's specific requirements. The project managers should send periodic reports of the performance evaluation of every employee, which are useful to the HR managers for the performance appraisal.

The project managers will set the key result areas (KRAs) of each member to be useful for the HR manager to prepare a detailed report on the performance appraisal form for each employee. The KRA helps in indicating the type of tasks the individual has achieved from the project. There should be a good combination of both individual as well as team-based performance evaluation in order to clearly understand the deeper insight of the performance level of the team.

The meetings are conducted formally every week and sometimes once in a month depending on the urgency of project completion. HR will not be involved in these meetings but will be briefed regularly about the overall proceedings. The project manager should be involved in the recruitment process with the HR manager because certain skill sets will be identified based on the requirements of specific projects. The project managers face many challenges in providing training to the employees. The main reason is due to the lack of:

- Understanding of subject knowledge

- Unknown training requirements

- Absence of innovative ideas during the training process

- Lack of motivation to undergo the training process

- Lack of understanding of technical skills

- Technology gap is too wide.

HR policies should be transparent in terms of framing the performance appraisal. They should be fair and open and HR should always get involved in the support activities for the team. HR managers should be realistic in their approaches. They should also ensure success of projects and by providing timely manpower to the project managers.

\section{In-depth interview questionnaire for HR managers}

HR's coordination with the project manager starts with identifying the right kind of talents for the right kind of job. The project manager will give new requirements regarding the people required for that project. The HR manager will look into the internal and external databases for sourcing and identification of talents. The HR manager checks about whether a proper performance evaluation has been done by the project managers. The role of the project manager is to support HR in handling the performance evaluation process effectively. The performance appraisal procedure carried out by the HR manager can be done on a weekly or daily basis depending on the need for the appraisal system to be implemented successfully. It is the responsibility of HR to conduct the performance evaluation of the completed project.

The compensation strategy has been designed depending on the industry rates and the standard compensation procedure followed across organisation. The compensation also depends on the demand level of skill sets. The selection strategies applied varies across the organisation but have some things in common. The selection depends on the right attitude on the part of the candidate, 
and is based on a particular technical skill set. The HR manager takes into consideration the project manager's opinion when making decisions involving selection strategies.

The analysis suggests that the mechanism for addressing employee grievances should be introduced in the project timeline. The project manager should respond to the grievance reports issued by the HR manager and HR manager should have close contact with the project manager. Employee engagement activities are common across all IT-oriented companies and HR follows a common procedure for it. The employee engagement activities involve team get-togethers and an informal social culture within teams. The employees' participation is very important since they are highly dependent on each other.

The analysis concludes that HR should be more involved in the organisation's future orientation and should be closely associated with the internal operations in addition to its support activities.

\section{Expert analysis on the role of $\mathrm{HR}$ in project-oriented teams}

The project manager has an important role to play in project-oriented team performance. HR should be involved in a support activities with the project manager. The responsibility of HR is to motivate employees to reduce the staff attrition rate. The main role of HR is to support the project managers in selecting the right kind of talents for the right kind of jobs. The challenge for $\mathrm{HR}$ is to source the talents for particular competencies based on specific requests from the project manager.

HR is an ongoing function and it works in parallel with other departments and supports them with the right kind of resources. This is the reason why HR is not treated as a main line function. HR plays an important role in manpower management.

\section{Steps to be taken to give more power to the HR manager}

- The HR manager should have more reporting power and should coordinate with the managers from other departments in order to execute the strategies efficiently.

- The performance appraisal system should be effective in managing the employees.

- The performance appraisal system should be managed by the HR manager.

- The HR team should be given the responsibility for training and development so that they can improve the quality of resources.

- The HR manager should be involved in core activities in order to help employees settle in and handle any grievances.

- The recruitment process should be managed by the HR manager.

- There should be an equitable distribution of manpower in the organisation.

\section{Key findings}

The analysis of the data from the survey of several team members and managers revealed some findings that explain the overall HR coordination with the project team members. 


\section{Team members' view}

- The team members felt that HR plays a supporting role in handling the team's functional aspects but doesn't deal with any internal functions within the project.

- HR's primary role is to carry out the employee engagement and performance evaluation activities as the core functions, with the selection process as a part of its support function.

- The team members suggested that there should a good balance of individual as well as team-based performance evaluation.

- The team members urged on a need for conducting more practice-oriented training implementation and wanted HR to take initiatives effectively regarding the changes to be made.

- The communication gap between HR, team members and other employees is wide, and this should be reduced in order to bring improve the performance evaluation of each team member.

\section{Project managers' view}

- The project manager coordinates with the HR manager in order to evaluate the proper skill sets required for the job. They felt that HR should be involved as a support activity and should concentrate more on the employee engagement and performance evaluation activities in an efficient way.

- The project managers felt that HR should get involved in team meetings but should not be involved in the decision-making process, which should be left to the project managers.

- It is the responsibility of the HR manager to strategise the recruitment process by getting the necessary skill set requirements from the project managers.

- The project managers felt that the HR policies should be transparent in terms of the performance appraisal. The HR policies should be fair and open and HR should always be involved in the team's support activities.

- The HR managers should ensure project $s$ and should give timely availability of manpower to the project managers

\section{HR managers' view}

- The HR manager felt that theirs was more of a supporting role than an involvement in core functions with the project managers.

- The HR managers' role is to check whether a proper performance evaluation has been made by the project managers

- Their role is to collect the requirements from the project managers for the efficient creation of the performance appraisal procedure and its implementation.

- The HR managers felt that they were the primary decision makers for strategies in the selection process based on the skills requirements given by the project managers.

- The HR manager plays a major role in employee engagement activities which involve team get-togethers and the informal culture within the teams

\section{Expert analysis of the role of $\mathrm{HR}$}

- The experts felt that HR is an ongoing function and it works parallel with other departments to support them with the right kind of resources. 
- The experts believed that the HR manager should have more reporting power and should coordinate with managers from other departments to execute the strategies efficiently.

- The HR managers should be actively involved in the core activities and to handle employee grievances efficiently.

- The experts felt that HR is considered an effective employee management function used in supporting the other departments in a unique way.

\section{Business function-specific findings of the case study}

Business partner and engagement role

- Support team in handling functional aspects.

- Undertake employee engagement and build this into the design and interventions.

- Support teams in creating better engagement.

- Contribute meaningfully in team meetings, without necessarily interfering in team decision making.

- Coordinate with the managers from other departments in order to execute the strategies efficiently.

- Handle employee grievances and address them properly through involvement in 'core' activities.

- Support the project teams in a unique way. Also create an informal culture among teams.

- Understand the cross-cultural diversities in order to create greater unity within the team and ensure better interpersonal relationships.

\section{Performance management role}

- Plan and execute performance evaluation activities.

- Create transparency in framing the performance appraisal plan. Make it a fair, open and participative process.

- Collect the requirements from the project managers for the efficient creation of a performance appraisal procedure and its implementation.

- Create a balance between individual and team-based performance while planning performance evaluations.

- Bridge the communication gap between team members through better team-based performance evaluations.

- Assist project managers in carrying out the performance appraisal process properly.

\section{Training and development role}

- Build a proper skills inventory for each job.

- Conduct more practice-oriented training.

- Conduct competency-based training.

\section{Hiring role}

- Create better job descriptions by closely aligning with the project managers.

- Strategise the recruitment process through aligning the requirements of the project managers with the hiring tools and sources and the selection methods and procedures.

- Ensure timely availability of manpower resources in successor projects.

- Ensure equitable distribution of manpower in the organisation. 


\section{Compensation management role}

- Assist project managers in compensation decisions.

- Design compensation strategies in line with industry practices.

\section{Discussion}

This section aims to compare the findings of this case study with the theories discussed in the literature review section.

Theories discussed in literature review

A trend in 'Projectification' has been identified, accompanied by increased research interest in project management (Soderland 2004). Also, the increased use of project-based structures has been accompanied by a shift from bureaucratic to post-bureaucratic organisations (Hatch 1997; Heydebrand 1989). As a discipline, project management has been used to increase process flexibility and autonomy. The increased use of project-based structures implies that projects have become an increasingly common work environment. This means that more time is spent on project work (Packendorff 2002; Whittington et al 1999).

Projects have now become the basic unit for core activities in contemporary organisational forms (Hobday 2000; Sydow et al 2004). Project-based structures have positive implications for management, employee relations and employment contracts, in terms of increased commitment, dynamism, support and solidarity, communication and group autonomy (Hovmark \& Nordkvist 1996).

It has also been seen that project-based structures create a continuously high intensive work environment that has negative implications on employees by substantially increasing their workload. This is more so in multi-project environments where the risk of excessive workload with little time for reflection, learning and recuperation between projects is enhanced (Packendorff 2002; Zika-Viktorsson, Sundstrom \& Engwall 2006).

The temporal nature of project-based structures creates a new work environment that is characterised by:

1. Higher role strain.

2. Stress reactions.

3. Less time available to the individual for competence development.

There is greater responsibility placed on the individual for competence development and professional development to remain employable (Goodman 1981; Zika-Viktorsson, Sundstrom, \& Engwall 2006; Packendorff 2002; Huemann, Turner \& Keegan 2004; Bredin \& Soderlund 2006; Grabher 2002). In project-based organisations, the important elements of permanence are lost and hence the emphasis is more on selection and turnover, rather than on training and learning (March 1995).

Research and study of human resource management in project-based organisations has assumed high significance (Geraldi 2008; Engwall, et al 2003: 130; Stulgienė \& Čiutienė 2012; Midler 1995; Whittington et al 1999: 591), because: 
1. Project-based structures are becoming increasingly common, especially in knowledgeintensive organisations.

2. The new work environment challenges some existing models of HRM.

3. Since projects are discontinuous, short-term and complex activities, more HR involvement is required to ensure the creation of a unique product or service. HR has to find ways of linking project organisations to individual goals.

4. From an individual employee perspective, factors like motivation, commitment, empowerment, job satisfaction, time pressure, and medical stress seem to be reconceptualised in the projectified context.

\section{Case study findings}

In choosing Zygus Engineering as the case focus of the research, an attempt was made to study a project-based organisation facing challenges in the way it operated with a temporal business model that needed to be tweaked based on the project undertaken.

The complexities of managing human capital at Zygus provided for a comprehensive study of human resource engagement issues at a project-based organisation. One of the toughest challenges that such organisations face is improving team interfaces and thereby impacting process improvements. At the core of such initiatives at the team interface level lies enhanced interventions at the HRM level.

The findings indicate the need for increased involvement by the project manager in setting KRAs for the employees, competency mapping, project coordination and recruitment and selection to identify the right kind of talent for the right kind of jobs in the respective projects. Such involvement by the project manager always has a positive impact.

The findings clearly indicate that project team members, in general, found HR wanting in many areas and believe that HR should:

1. $\quad$ Provide necessary feedback to aid performance.

2. $\quad$ Provide necessary resources.

3. Take up employee engagement activities to create more motivation and cross-cultural diversity.

4. $\quad$ Provide more performance-based incentives.

5. Have a good combination of both individual and team-based performance evaluations.

6. Make training more practical.

7. $\quad$ Reduce the communication gap between them and project managers.

8. Ensure better work-life balance to positively impact employee job satisfaction.

The findings show that the most team members felt that practical implementation aspects are missing in the training process. The project managers also felt that they faced many challenges in providing training to the employees. The main reasons for this are:

1. Insufficient subject knowledge.

2. Unknown training requirements.

3. Absence of innovative ideas during the training process.

4. Lack of motivation to undergo training.

5. Lack of understanding of technical skills. 


\section{Technological gap is wide.}

Clearly the focus on training and learning has been insufficient and continues to be a challenge.

The HR function at Zygus plays more of a support role, rather than being involved in the core functionals with the project managers. However, the experts were of the opinion that the HR manager should have more reporting power and should coordinate with the managers from other departments in order to execute the strategies efficiently. They also felt that the HR managers should be actively involved in the core activities in order to help employees settle in and to handle their grievances efficiently. HR plays a major role in the employee engagement activities which involves team get-togethers and the informal culture within the teams.

The findings clearly recommend a greater involvement by HR and that it should play the following roles effectively in the organisation to ensure greater success of the project-based structure at Zygus Engineering:

1. Business partner and engagement role;

2. $\quad$ Performance management role;

3. Training and development role;

4. Hiring role; and

5. Compensation management role.

The case study findings find resonate with the theories discussed in the literature review and clearly show that project-based structures lead to the creation of a new work environment and associated complexities in organisations. This, coupled with the temporal nature of the projectbased structures, exert various kind of strains on the HR of the organisation and hence emphasizes the need for greater involvement of HR, and also a need for HR to continuously reinvent itself.

\section{Conclusion}

Contemporary organisations are increasingly embracing project-based structures. Project-based organisations have far greater complexity compared to traditional organisations owing to their temporariness. Such temporariness gives project-based organisations characteristics like time, task, team and transition that in turn might affect the project-based organisation. This research aimed to analyse the case of a prominent project-based organisation and the role that HRM can play to efficiently manage and effectively engage the employees, and thus contributes learning that can be extrapolated to similar project-based organisations to manage HR better.

\section{Directions for future research}

Future research on allied topics could focus on specific HR challenges and study them in greater detail across project-based organisations. For example, engagement challenges could be studied in detail in various project-based organisations. Research could also be undertaken with respect to particular types of project-based organisations across a various industry sectors like IT, gas and petrochemicals, and consultancy. 


\section{References}

(eds.): Strategies of Qualitative Inquiry. Thousand Oaks, London, New Delhi: Sage.

Agarwal N., Rathod U. 2006, Defining success for software projects, International Journal of Project Management, vol. 24, no.4, 358-370.

Atkinson R. 1999, Project management: cost, time and quality, two best guesses and a phenomenon, its time to accept other success criteria, International Journal of Project Management, vol. 17, no.6, 337-342.

Baccarini, D. 1999, The logical framework method for defining project success, Project Management Journal, 2532.

Baccarini, D.1996, The concept of project complexity - a review, International Journal of Project Management, vol. No. 14, 201-204.

Benbasat I., Goldstein D. \& Mead M. 1987, The case research strategy in studies of information systems, MIS Quarterly, vol. 11, 369-386.

Border transfer of knowledge: cultural lessons from Project GLOBE 2005, Academy of Management Executive, vol. 19, no. 2, 59-76.

Bredin, K. \& Soderlund, J. 2006, HRM and project intensification in R\&D-based companies: a study of Volvo Car Corporation and AstraZeneca, R\&D Management, vol. 36, no. 5, 467-485.

Castells, M. 1996, The Rise of the Network Society, Blackwell: Oxford.

Freeman, M., Beale, P. 1992, Measuring project success, Project Management Journal, vol. 23, no.1, 8-17.

Geraldi, J. 2008, The thermometer of complexity, Project Perspectives, The Annual Publication of the International Management Association, 4-9.

Goodman, R. 1981, Temporary Systems: Professional Development, Manpower Utilization, Task Effectiveness, and Innovation, Praeger: New York.

Grabher, G. 2002, Betwixt and between: temporary employees as liminal subjects in flexible organization, Organization Studies, vol. 20, no. 4, 601-617.

Groat, L. \& Wang, D. 2002, Architectural Research Methods, John Wiley: New York.

Hallgreen, M. \& E. Maaninen-Olsson 2005, Deviations, ambiguity, and uncertainty in a project-based organization, Project Management Journal, vol. 36, no. 3, 17-26.

Hansen, M. 2002, Knowledge networks: explaining effective knowledge sharing in multiunit companies, Organization Science, vol. 13, no. 3, 232-248.

Hansen, M., Nohria N. \& T. Tierney 1999, What is your strategy for managing knowledge?” Harvard Business Review, vol. 77, no. 2, 106-116.

Hjelm, M. 2003, Knowledge management in the project management environment, Masters thesis, Department of Industrial Engineering and Management Systems, University of Central Florida.

Hobday, M. 2000, The project-based organisation: an ideal form for managing complex products and systems?' Research Policy, vol. 29, no. 7/8, 871-894.

Huemann, M., Turner, R. \& Keegan, A. 2004, Managing Human Resources in a Project-oriented Company, The Wiley Guide to Managing Projects, http://onlinelibrary.wiley.com/doi/10.1002/9780470172391.fmatter/pdf (accessed Jun 2013).

Hyväri, Irja, 2006, Success of projects in different organizational conditions, Project Management Journal, Vol. 37, No. 4, 31-41, ISSN 8756-9728/03

Inkpen, A.C. (1996) “Creating knowledge through collaboration”, California Management Review, Vol 39, No. 1, pp 123-140.

Jang Y. \& Lee J. 1998, Factors influencing the success of management consulting projects, International Journal of Project Management, vol. 16, no.2, 67-72.

Javidan, M., Stahl, G. Brodbeck, F. \& Wilderom, C. 2005, “Cross-border transferof knowledge: cultural lessons from Project GLOBE, Academy of Management executive, vol. 19, 59-76.

Johansson, Rolf. 2002, Ett explikativt angreppsssätt - Fallstudiemetodikens utveckling, logiska grund och betydelse i arkitekturforskningen, Nordic Journal of Architectural Research, vol. 53, no 2, 19-28.

Karlsen, J. \& P. Gottschalk 2004, Factors affecting knowledge transfer in IT projects, Engineering Management Journal, vol. 16, no. 1, 3-10.

March, J. 1995, The future, disposable organizations, and the rigidities of imagination, Organization, vol. 2, no. 3/4, 427-440.

Midler, C. 1995, Projectification of the firm: the Renault case, Scandinavian Journal of Management, vol. 11, no. 4, 363-375.

Myers, M.D. 2003, Qualitative research in information systems’ MISQ Discovery, www.qual.auckland.ac.nz (accessed Jan 2014). 
Packendorff, J. 2002, The temporary society and its enemies, projects from an individual perspective. In K. SahlinAndersson, \& A. Soderholm, Beyond Project Management: New Perspectives on the Temporary Permanent Dilemma (pp. 39-58). Copenhagen Business School Press: Copenhagen.

Rockart, J.F. 1982, The changing role of the information system executive: a critical success factor perspective, MIT Sloan Management Review, vol. 23 no. 3, 3-13.

Stake, Robert. (1998). “Case Studies” in: Norman Denzin \& Yvonna Lincoln.

Stulgienè, A. \& Čiutienè, R. 2012, HRM challenges in transition to project management, Economics and Management, vol. 17, no. 3, 1215.

Turner R.J. 2004, Five necessary conditions for project success, International Journal of Project Management, vol. 22, no.5, 349-350.

Turner, R.J. 1999, The Handbook of Project based Management, 2nd ed., McGraw-Hill: London.

Zika-Viktorsson, A., Sundstrom, P. \& Engwall, M. 2006, Project overload: an exploratory study of work and management in multi-project settings, International Journal of Project Management, vol. 24, no. 5, 385394.

\section{About the authors:}

Dr Debashish Sengupta is Associate Professor of Strategic Human Resource Management at the School of Business, Alliance University, Bangalore, India. His research interests are in the area of engagement and Generation Y. Debashish has had a stint of about one and half decades in academia and has published extensively. He also has an interest in studying human resource challenges in project-based organisations.

Email: debashish@alliance.edu.in

Ray Titus is the Professor of Marketing \& Strategy at the School of Business, Alliance University, Bangalore, India. Ray's research interests lie in the area of consumption behaviour, marketing value propositions, and new and social media landscape. His entry into academia followed a decade-long stint in industry where he served in operations, marketing and project roles.

Email: ray.titus@alliance.edu.in 